\title{
A Rare Case of a Tracheal Fibroepithelial Polyp Treated by an Endobronchial Resection
}

\author{
Atsuhito Ushiki ${ }^{1}$, Masanori Yasuo ${ }^{1}$, Tsuyoshi Tanabe ${ }^{1}$, Kazuhisa Urushihata ${ }^{1}$, \\ Hiroshi Yamamoto ${ }^{1}$, Masayuki Hanaoka ${ }^{1}$, Tomonobu Koizumi ${ }^{1}$, Keisaku Fujimoto ${ }^{1}$, \\ Keishi Kubo ${ }^{1}$, Yoshitaka Yamazaki ${ }^{2}$ and Koji Asano ${ }^{3}$
}

\begin{abstract}
This report describes a very rare case of a tracheal fibroepithelial polyp. A 69-year-old male had been treated in this department because of chronic obstructive pulmonary disease since 2006. In July 2007, chest computed tomography revealed a bronchial tumor located at the distal end of the trachea. A bronchoscopic examination revealed a multilocular polyp. An endobronchial resection was performed to remove the lesion. A tracheobronchial fibroepithelial polyp is very rare. We herein describe and discuss the appropriate therapeutic policy and also review the pertinent literature.
\end{abstract}

Key words: fibroepithelial polyp, tracheobronchial tumor, endobronchial resection, electrosurgical snare

(Inter Med 47: 1723-1726, 2008)

(DOI: 10.2169/internalmedicine.47.1241)

\section{Introduction}

A fibroepithelial polyp is a common type of tumor in the skin, vulva, and the neck of uterus, but it is very rare in the trachea (1). A tracheobronchial fibroepithelial polyp is one of the inflammatory polyps. The etiology seems to be related to chronic inflammatory processes (2). Histopathologically, this polyp is fibroinflammatory and lined with respiratory epithelium with an edematous stroma. As far as we know, only three cases have been previously reported in either the English or the Japanese medical literature (1, 3, 4). Here, we describe a rare case of a tracheal fibroepithelial polyp while also reviewing previous reports describing this type of lesion.

\section{Case Report}

A 69-year-old man was referred to this department for further evaluation of an obstructive ventilatory impairment which was found during a preoperative examination for gastric cancer in March 2006. He was diagnosed to have chronic obstructive pulmonary disease (COPD), and he remained under observation in this department.

In July 2007, a tracheal polyp was detected by chest computed tomography (CT). This patient had no respiratory symptoms. He smoked three packs of cigarettes per day prior to undergoing surgery for gastric cancer. CT revealed a distal tracheal tumor. Subsequent flexible bronchoscopy revealed that a pedunculate multilocular polyp that had grown from the left lateral wall of the distal end of trachea (Fig. 1A). The surface of the tumor was lustrous. No specimen could be obtained using biopsy forceps because the polyp was firm. Therefore, the polyp was scheduled to be removed using an electrosurgical snare with a flexible bronchoscope. The equipment for the electrosurgical snare was an ICC 200 (Erbe Elektromedizin;Tuebingen, Germany). The electrosurgical snare (SD-7P-1, Olympus, Tokyo) was put into the working channel of a flexible bronchoscope (BF 1T-260, Olympus). A single endobronchial resection was performed using the electrosurgical snare and the resected tumor was removed using grasping forceps (FG-42 L-1, Olympus). Most of the tumor was resected by this maneuver. Furthermore several short 1 to $2 \mathrm{~s}$ bursts of argon

\footnotetext{
${ }^{1}$ The First Department of Internal Medicine, Shinshu University School of Medicine, Matsumoto, ${ }^{2}$ Department of Endoscopy, Shinshu University School of Medicine, Matsumoto and ${ }^{3}$ Department of Laboratory Medicine, Shinshu University School of Medicine, Matsumoto Received for publication April 23, 2008; Accepted for publication June 10, 2008
} Correspondence to Dr. Masanori Yasuo, yasumasa@shinshu-u.ac.jp 


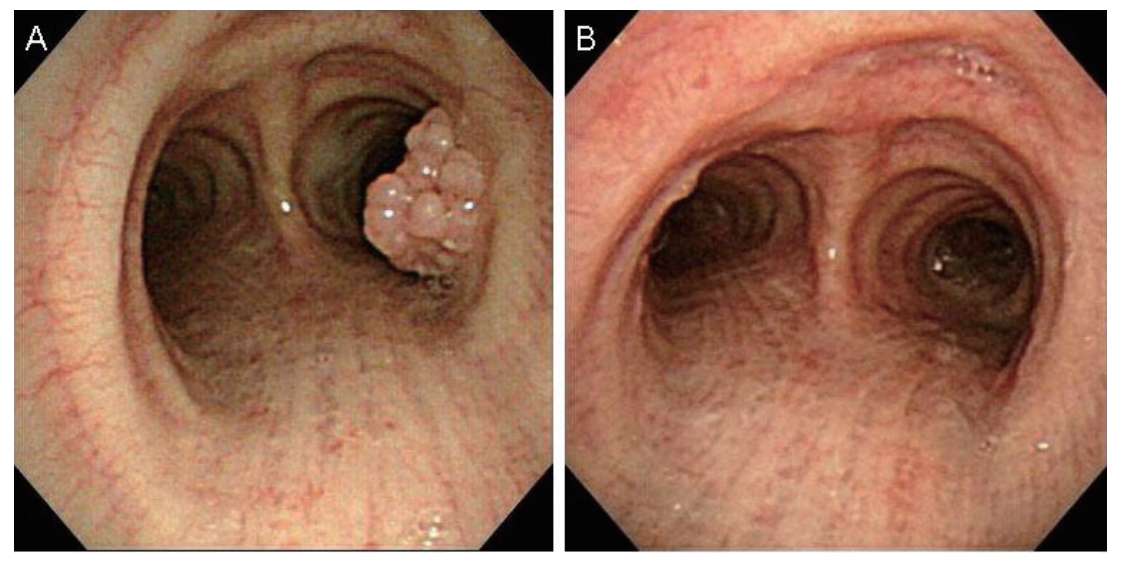

Figure 1. A: Bronchoscopic findings of the tumor. The surface of the multilocular polyp was lustrous. B: Bronchoscopic findings 6 months after the tumor resection. No recurrence was observed at the site of the resection.

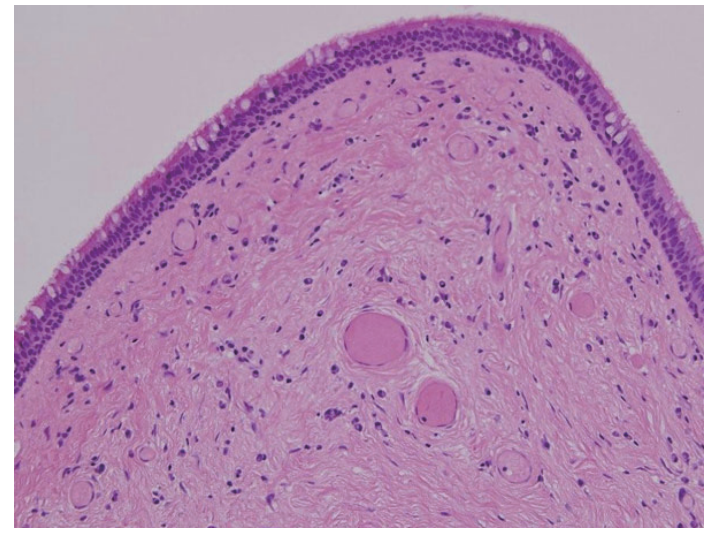

Figure 2. The resected specimen revealed that the polyp was lined with normal respiratory epithelium and contained a fibrovascular stroma with mononuclear inflammatory cells. Hematoxylin and Eosin staining (original magnification 200x).

plasma coagulation (APC) were administered at the sites of the resection for further coagulation of the residual tumor. A flexible-monopolar Teflon tube with a $1.5 \mathrm{~mm}$ diameter, 150 $\mathrm{cm}$ length was used for the APC. Oxygen was administered at a rate of two liters per minute through a nasal cannula during the bronchoscopy. The diagnosis of a fibroepithelial polyp was made following an examination of the pathological specimen. A specimen which was lined with a normal respiratory epithelium and fibrovascular stroma with mononuclear inflammatory cells is shown (Fig. 2).

Surveillance bronchoscopy 6 months after the tumor resection showed that the resected site and trachea remained patent and no recurrence had occurred (Fig. 1B).

\section{Discussion}

The current patient had a very rare tracheal fibroepithelial polyp and underwent an endobronchial resection. Benign airway tumors are uncommon and account for only $1.9 \%$ of all respiratory tumors (5). A tracheobronchial fibroepithelial polyp is particularly rare. The cases of a tracheobronchial fibroepithelial polyp that have been previously reported in English and Japanese are summarized in Table 1. In 1938, Pollak et al reported 11 cases of fibroepithelial polyp in a summary of the literature pertaining to benign bronchial tumors and cited 27 cases recognized at autopsy and 77 encountered in living patients. Only one report has previously described a plural case, however no detailed data could be obtained from this article (6). Only three case reports are available to date $(1,3,4)$. Rowlands reported a case of intractable pneumonia in a 38-year-old man. Bronchoscopy revealed a multinodular polyp that was located below the level of the right upper lobe bronchial orifice. A biopsy specimen showed no neoplastic changes. Two weeks later, the middle and lower lobes of the right lung were resected. The resected polyp contained normal bronchial respiratory epithelium and a dense fibrovascular stroma containing scattered lymphocytic exudates. Although only a 2-month follow-up period was described, the patient had a good clinical course (3). Dincer et al reported a 55-year-old man patient who had been followed up because of recurrent pulmonary infections for 40 years. He has refused to undergo a surgical resection. Bronchoscopy revealed a mobile lobulated pinkish polypoid lesion protruding from the trachea. The right lower lobe of his lung was thought to be dysfunctional because of cystic bronchiectatic changes revealed by chest CT. As a result, he underwent a right lower bilobectomy. The pathological examination revealed a fibroepithelial polyp that originated from the right middle lobe bronchus. He has been in favorable health for 10 months (4). Komatsu et al reported a 37-year-old woman who had repetitive episodes of bronchopneumonia. Bronchoscopy revealed a polypoid lesion occluding the right $\mathrm{B}^{6}$. The polypoid lesion was endoscopically resected by an electrosurgical snare. APC was administered to cauterize the residual lesion. The pathological examination revealed a fibroepithelial polyp. The patient had no recurrence for 2 years (1).

Recently the European Respiratory Society and American Thoracic Society issued a statement concerning interven- 
Table 1. Case Reports of Tracheobronchial Fibroepithelial Polyp

\begin{tabular}{|c|c|c|c|c|c|c|}
\hline Authors & Age & Sex & $\begin{array}{l}\text { Past history or } \\
\text { underlying } \\
\text { disease }\end{array}$ & Therapy & $\begin{array}{l}\text { Follow up } \\
\text { (months) }\end{array}$ & $\begin{array}{l}\text { Ref. } \\
\text { No }\end{array}$ \\
\hline $\begin{array}{l}\text { Komatsu Y } \\
\text { et al. }\end{array}$ & 37 & $\mathrm{~F}$ & $\begin{array}{l}\text { repetitive } \\
\text { pneumonia for } 1 \\
\text { year, atopic } \\
\text { dermatitis }\end{array}$ & $\begin{array}{l}\text { Endobronchial } \\
\text { resection }\end{array}$ & 24 & 1 \\
\hline $\begin{array}{l}\text { Rowland } \\
\text { DT Jr }\end{array}$ & 38 & $\mathrm{M}$ & $\begin{array}{l}\text { repetitive } \\
\text { pneumonia for } 5 \\
\text { years, two attacks } \\
\text { of pertussis }\end{array}$ & $\begin{array}{l}\text { Surgical } \\
\text { resection }\end{array}$ & 2 & 3 \\
\hline $\begin{array}{l}\text { Dincer I et } \\
\text { al }\end{array}$ & 55 & $\mathrm{M}$ & $\begin{array}{l}\text { repetitive } \\
\text { pneumonia for } 40 \\
\text { years }\end{array}$ & $\begin{array}{l}\text { Surgical } \\
\text { resection }\end{array}$ & 10 & 4 \\
\hline Our case & 69 & $\mathrm{M}$ & COPD & $\begin{array}{l}\text { Endobronchial } \\
\text { resection }\end{array}$ & 6 & \\
\hline
\end{tabular}

COPD: chronic obstructive pulmonary disease, Ref.: reference

tional pulmonology' techniques (7). Electrosurgical snare and APC are one of the modalities in interventional pulmonology. The immediate efficacy is now widely recognized (8-11). An electrosurgical snare and APC was also used in the current case for the resection of a fibroepithelial polyp. A tracheobronchial fibroepithelial polyp is composed of collagen fibers in a stroma covered with normal respiratory epithelium. It is thought to be an inflammatory polyp. Although the etiology is unclear, the polyp seems to be related to chronic inflammatory processes (2). It may be caused by chronic infection, foreign body aspiration, chronic smoke inhalation, chemical stimulation, and prolonged mechanical ventilation. In the current case, although heavy smoking and chronic inflammation of COPD may be one of the causes for this polyp, the exact cause is unknown.

Considering the etiology of this tumor, it not associated with neoplastic change or recurrence. Indeed, although the longest follow-up period is only 2 years (1), no recurrence and metastasis has been reported. In this current case, no recurrence or metastasis was seen in the clinical course (6 months). Recently, the adjunct use of APC has been reported to be safe and efficacious after a gastroenterological polyp resection (12). In this report, significantly lower recur- rence rates were indicated in the APC group in comparison to the non-APC (control) group (12). Therefore, additive coagulation by APC is usually administered at the site of a polypectomy in our institution $(1,11)$. However, in the current case, since recurrence is rarely seen with fibroepithelial polyps, additive coagulation may not have been necessary, based on surveillance bronchoscopy (1).

In the case of a bronchial fibroepithelial polyp, several patients underwent a surgical resection $(3,4)$. The reasons why endobronchial intervention was not used was because either endobronchial intervention had not yet been developed (3) or there was diffuse bronchiectasis and fibrosis due to a recurrent infection (4). No optimal therapy has been established due to the rarity of this type of tumor. However, surgical resection appears to be unsuitable for this tumor. Further accumulation of knowledge about this tumor will therefore be needed.

In summary, a case of tracheal fibroepithelial polyp was treated with an endobronchial resection. Because a tracheobronchial fibroepithelial polyp is very rare, the experience of this case was described and the previously reported cases were discussed.

\section{References}


28: 310-313, 2006 (in Japanese, Abstract in English).

2. Tedeschi LG, Libertini R, Conte B. Endobronchial polyp. Chest 63: 110-112, 1973.

3. Rowlands DT Jr. Fibroepithelial polyps of the bronchus: A case report and review of the literature. Dis Chest 37: 199-202, 1960.

4. Dincer I, Demir A, Akin H, Melek H, Altin S. A giant endobronchial inflammatory polyp. Ann Thorac Surg 80: 2353-2356, 2005.

5. Shah H, Garbe L, Nussebaum E, Dumon JF, Chiodera PL, Cavaliere B. Benign tumors of the tracheobronchial tree. Endoscopic characteristics and role of laser resection. Chest 107: 1744-1751, 1995.

6. Pollak BS, Cohen S, Gnassi AM. Inflammatory Bronchial Tumors. Archives of Otolaryngology 27: 426, 1938.

7. Bolliger CT, Sutedja TG, Strausz J, Freitag L. Therapeutic bronchoscopy with immediate effect: laser, electrocautery, argon plasma coagulation and stents. Eur Respir J 27: 1258-1271, 2006.
8. Yasuo M, Tanabe T, Tsushima K, et al. Endobronchial argon plasma coagulation for the management of post-intubation tracheal stenosis. Respirology 11: 659-662, 2006.

9. Yasuo M, Furuya S, Kanda S, et al. Successful endoscopic dilatation to alleviate airway suffocation in a case with esophageal cancer after stent implantation. Intern Med 46: 1745-1748, 2007.

10. Yasuo M, Tanabe T, Tsushima K, et al. Endobronchial argon plasma coagulation for the palliation of recurrent tracheobronchial adenoid cystic carcinoma. J Bronchol 14: 278-280, 2007.

11. Matsubara M, Yasuo $M$, Tanabe $T$, et al. Pleomorphic adenoma with an endobronchial resection. Intern Med 47: 1117-1120, 2008.

12. Brooker JC, Saunders BP, Shah SG, Thapar CJ, Suzuki N, William CB. Treatment with argon plasma coagulation reduces recurrence after piecemeal resection of large sessile colonic polyps: a randomized trial and recommendations. Gastrointest Endosc 55: 371-375, 2002.

(C) 2008 The Japanese Society of Internal Medicine http://www.naika.or.jp/imindex.html 